Original Article

\title{
COM PARE KNOWLEDGE ON SELF CARE MANAGEMENT OF PREGNANCY INDUCED HYPERTENSION BETWEEN PRIMI GRAVID AND MULTIGRAVIDA
}

\author{
Prathima P. \\ Assistant Professor \& HOD , Department of OBG, Universal College of Nursing \\ Bennarghatta Main Road, Bangalore - 76, Karnataka, India. \\ Correspondence : \\ Prathima P. \\ Assistant Professor \& HOD, Department of OBG, Universal College of Nursing, IIM B Post, Arekere, Micolayout, \\ Bennarghatta M ain Road, Bangalore - 76, Karnataka, India \\ Mobile: +91 9986778622 E-mail: prathima_1978@ymail.com
}

\begin{abstract}
:
Objectives: to assess and compare the knowledge on self-care management of pregnancy induced hypertension among primi gravid and multi gravida mothers.

Method: A non-experimental descriptive comparative was conducted between 40 primi gravida mother and 40 multi gravida mothers who were selected by using purposive sampling to assess knowledge on self-care management of pregnancy induced hypertension. Self-structured questionnaire was used to collect the data. Appropriate Descriptive and inferential statistics were used to analyse data and to draw inferences.

Results: $55 \%$ of primi gravida mothers and $40 \%$ of multi gravid mothers had inadequate knowledge. Only $2.5 \%$ of primi gravida and $5 \%$ of multi gravida mothers had adequate knowledge. Respondents from primigravida had knowledge about $31.8 \%$ and $38.6 \%$ regarding signs \& symptoms and Preventive measures. $35 \%$ and $44.7 \%$ of multi mothers were aware about signs \& symptoms and preventive measures respectively. Which shows all the respondent were less aware about pregnancy induced hypertension. And there is an association between age \& M onthly income on knowledge level.
\end{abstract}

Conclusion: There is a necessity to provide information for those specific at risk population. Which helps to increase the knowledge, develop positive attitude, prevent complications and to have better maternal and child health.

Key words: Pregnancy induced hypertension, Self-care management, HELLP and eclampsia.

\section{Introduction:}

Pregnancy and childbirth are special events in women's lives and indeed, in the lives of their families. This can be a time of great joy and joyful anticipation. It can also be a time of fear, suffering and even death. Even though pregnancy is not a disease; but a normal physiological process, it is associated with certain risks to the health and survival both for women and neonates, pregnancy induced

\begin{tabular}{|c|}
\hline Access this article online \\
\hline Quick Response Code \\
\hline
\end{tabular}

complications like imminent eclampsia, eclampsia and HELLP syndrome can be averted. The association between primi parity and pre-eclampsia is so widely accepted that it is at the core of several patho physiological theories. For example, it has been proposed that pre-eclampsia is the consequence of a maternal immune reaction against paternal antigens expressed in the placenta and that this reaction might result in defective trophoblast invasion and subsequent placental dysfunction. The lower risk of preeclampsia among multiparous women has been attributed to desensitisation after exposure to paternal antigens in the placenta during previous pregnancies. The lower risk has also been attributed to smoother trophoblastic invasion after modification of maternal spiral arteries during the first pregnancy. ${ }^{2}$ 
Ten million women develop preeclampsia each year around the world. Worldwide about 76,000 pregnant women die each year from preeclampsia and related hypertensive disorders. And, the number of babies who die from these disorders is thought to be on the order of 500,000 perannum. ${ }^{3}$

In developing countries, a woman is seven times as likely to develop preeclampsia as a woman in a developed country. From $10-25 \%$ of these cases will result in maternal death. ${ }^{4}$

Preeclampsia should be detected and appropriately managed before the onset of convulsions (eclampsia) and other life-threatening complications.

Health maintenance is an important aspect of prenatal care. Participation of the mother in the care ensures the prompt reporting of the possible problems. Prenatal care is one of the models of primary and secondary prevention of disease. In order to reduce the increasing maternal mortality rates, women with hypertensive disorders in pregnancy should be inform of their disease and satisfactory medical information should be provided by their health care providers. ${ }^{5}$

As a result of inadequate knowledge, negative attitude and lack of preventive practice will increases the incidences of complicating pregnancy with pregnancy induced hypertension. Maternal death could be prevented if women well able to have adequate knowledge and positive attitude towards attending antenatal clinic, utilize good health service and by following preventive practices. This study was aimed to compare the knowledge on self-care management of pregnancy induced hypertension between primi gravida and multi gravida mothers.

\section{Objectives:}

1. To assess the knowledge level on self-care management of Pregnancy Induced hypertension among primi gravida mothers.

2. To assess the knowledge level on self-care management of Pregnancy Induced hypertension among Multi gravida mothers.

3. To compare the knowledge level on self-care management of Pregnancy Induced hypertension between primi gravida mothers and multi gravid mothers.

4. To find out association between selected demographic variables and knowledge level on self-care management of pregnancy induced hypertension.

\section{Materials and methods:}

To achieve the objectives a descriptive comparative design was adopted. The population of the study included antenatal mothers in a hospital. Thus 80 mothers were selected using purposive sampling technique. Samples were 40 primigravida mothers and 40 multigravida mothers. This study was conducted in St. Mary hospital Bangalore.

A structured self-administered questionnaire was used to collect data. It consisted of two parts. Part - I was used to collect demographic data of pregnant women which includes age, education, religion, occupation, income and parity. Part- II that was aimed at assessing the knowledge on self-care management of Pregnancy Induced Hypertension. The questionnaire has 34 items which includes definition, risk factors, Signs and symptoms, preventive measures and complication. The knowledge level were classified based on the score obtained as inadequate $(<40 \%)$, moderately adequate (41 to $75 \%$ ), Adequate $(>76 \%)$.

The prepared tool was validated by experts. The reliability of the tool was found. Stability of the tool was checked by using test and retest method $(r=0.90)$, about reliability internal consistency was assessed through cronbach's alpha $(r=0.73)$. After obtaining permission from the hospital, the study was conducted. Data was collected through self-administered questionnaire.

Pregnant women who fulfil inclusion and exclusion criteria were selected. Purpose of the study was explained and oral consent was obtained from each participant and they were assured that study is only for academic purpose, information obtained from them will be kept confidential. The questionnaire was administered individually. The 
instructions were given in the beginning of the administration of the questionnaire. All the questions in the questionnaire are self-explanatory and multiple choice questions. Participants were requested to read the questions carefully to provide the information as best of their knowledge, on an average each participant took 40 45 minutes to complete the questionnaire.

\section{Analysis and Results:}

\section{I: Description of demographic characteristics}

In the present study it was found that $55 \%$ (22) of primi gravid mothers and $62.5 \%$ (25) of multigravida mothers were in the age group of $21-25$ years, $30 \%$ (13) of primi mothers educated up to UG, 32.5\% (13) of multigravida mothers were educated upto PUC, majority of the mothers were in Hindu religion $72.5 \%$ (29) and $62.5 \%$ (25) respectively from Primigravida and multigravida mothers. About their family monthly income $42.5 \%$ (17) of primi mothers income upto $15,000 /-$ and $30 \%$ (12) of multimothers income upto 10,000 , and $82.5 \%$ (33) and $90 \%$ (36) respectively from primigravida and multigravida mothers were homemakers.

\section{Level of knowledge:}

Knowledge level of primigravida and multigravida mothers: knowledge level on self-care management of PIH was 55\% of primigravida mothers were showing inadequate whereas in multi gravid mothers $40 \%$ were in the category of inadequate knowledge. Majority of them from multigravida mothers were coming under moderately adequate knowledge (55\%), in primi gravid mothers $42.5 \%$ were in this category. From both the group only $2.5 \%$ and $5 \%$ were showing adequate knowledge respectively from primi gravida and multi gravid mothers.

\section{Comparison of knowledge level}

In the present primi gravida mothers were demonstrating lesser knowledge in all the aspects. (Fig 3 and Table 1).

Independent t-test was computed to find out significant difference between the groups which was tested at 0.05 level, calculated value was 0.1044 which is lesser than table value i.e 2 hence it is accepted that there is no significant difference between the groups.

\section{Association between knowledge level and selected demographic variable.}

The chi-square value calculated for age is 3.76 which is more than table value that is 3.36 and for monthly income calculated value was 4.16 which is more than table value that is 3.36 hence it is significant. Which means there is significant association between the level of knowledge on self-care management and age and M onthly income.

Table 1: Shows comparison of mean scores between Primigravida and M ultigravida mothers.

\begin{tabular}{|c|c|c|c|c|c|c|c|}
\hline S.no & \multicolumn{2}{|c|}{ Mean } & \multicolumn{2}{|c|}{ Std } & Df & t-value & Table \\
\hline & Primi & Multi & Primi & M ulti & & & value \\
\hline 1 & 13 & 14.5 & 3.6 & 4.1 & 78 & 0.1044 & 2 NS \\
\hline
\end{tabular}

Table 2: Association between knowledge level and demographic variables.

\begin{tabular}{|c|c|c|c|c|c|c|c|}
\hline S.no & Variable & Below Median & Above Median & Total & Df & Chi-square value & Table Value \\
\hline 1 & Age in years & & & & \multirow{7}{*}{4} & \multirow{7}{*}{3.76} & \multirow{7}{*}{$3.36 \mathrm{~S}$} \\
\hline & $<20$ & 1 & 1 & 2 & & & \\
\hline & $21-25$ & 30 & 17 & 47 & & & \\
\hline & $26-30$ & 15 & 10 & 25 & & & \\
\hline & $31-35$ & 2 & 3 & 5 & & & \\
\hline & $36-40$ & 1 & 0 & 1 & & & \\
\hline & Total & 49 & 31 & 80 & & & \\
\hline 2 & Income & & & & \multirow{7}{*}{4} & \multirow{7}{*}{4.165} & \multirow{7}{*}{$3.36 \mathrm{~S}$} \\
\hline & $<5000$ & 9 & 6 & 15 & & & \\
\hline & $5001-10000$ & 19 & 8 & 27 & & & \\
\hline & 10001- 15000 & 16 & 9 & 25 & & & \\
\hline & $15001-20000$ & 4 & 6 & 10 & & & \\
\hline & $>20001$ & 1 & 2 & 3 & & & \\
\hline & Total & 49 & 31 & 80 & & & \\
\hline
\end{tabular}


Fig.1 Pie diagram of knowledge level among Primi -gravida mothers.

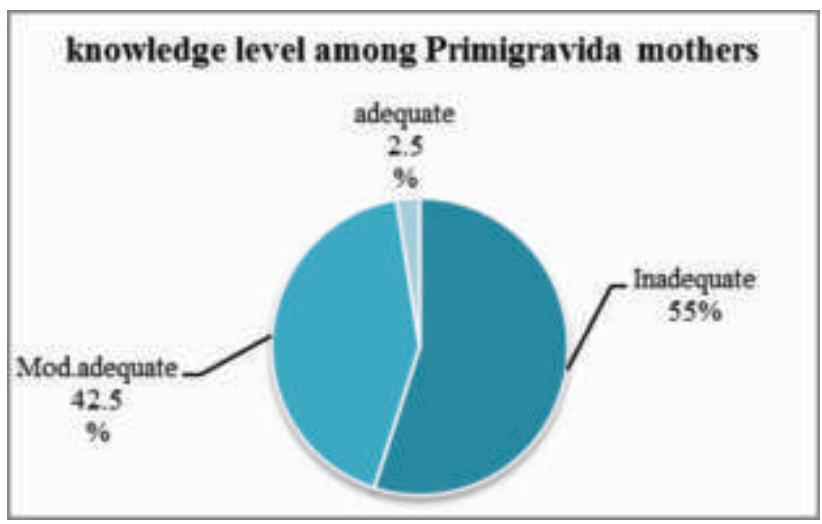

Fig.3 Bar Graph shows Area Wise comparison of knowledge on self care management between primi and Multigravida mothers.

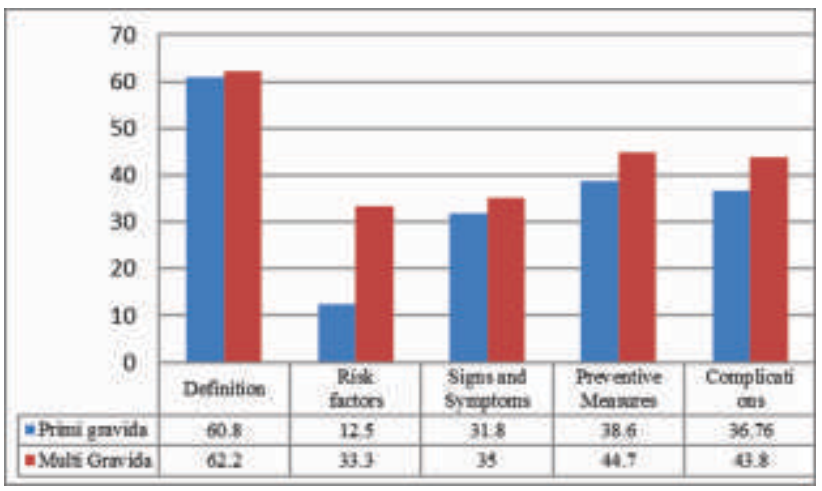

\section{Discussion:}

Approximately 800 women die from pregnancy or childbirth-related complications around the world every day. Ninety-nine percent occur in developing countries. The higher number of maternal deaths in some areas of the world reflects inequities in access to health services. The complications that account for $80 \%$ of all maternal deaths are severe bleeding (mostly bleeding after childbirth), infections (usually after childbirth), high blood pressure during pregnancy (preeclampsia and eclampsia), and unsafe abortion. The remaining $20 \%$ are associated with diseases such as malaria and AIDS during pregnancy. ${ }^{6}$

Maternal health and newborn health are closely linked. More than three million newborn babies die every year, and an additional 2.6 million babies are stillborn. ${ }^{7}$

In present study $55 \%$ of primigravida mothers and $40 \%$ of
Fig.2 Pie diagram of knowledge level among M ulti -gravida mothers.

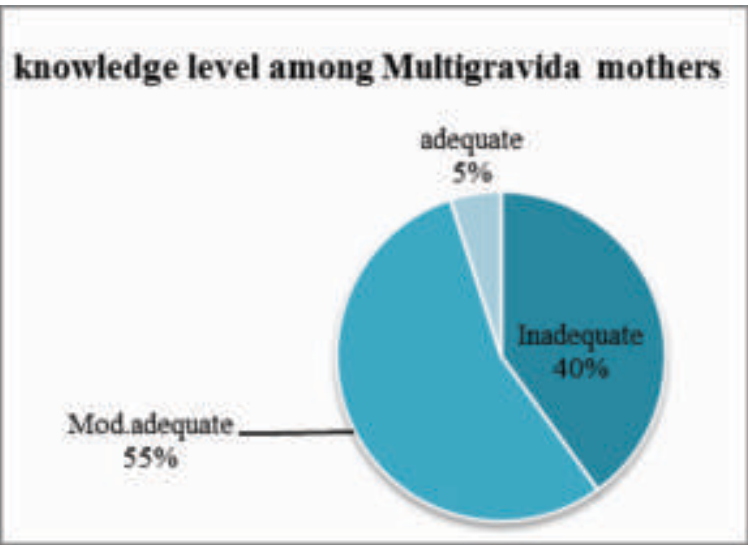

multi gravid mothers had inadequate knowledge. Only $2.5 \%$ of primigravida and $5 \%$ of multigravida mothers had adequate knowledge. $31.8 \%$ and 38.6 of primigravida mothers, $35 \%$ and $44.7 \%$ of multimothers were aware about signs \& symptoms and preventive measures respectively. Which shows they were less aware about pregnancy induced hypertension from both the group.

In Kerala, a study conducted on self-care activity of pregnancy induced hypertension and maternal outcome which revealed that $95 \%$ of pregnant women from both the experimental and control group had inadequate knowledge. Experimental group showed increased in knowledge score after teaching programme. ${ }^{8}$

Another study conducted to assess the level of knowledge of antenatal mother regarding prevention of pregnancy induced hypertension. The research design used for the study was Non-Experimental design. Purposive sampling technique was used to select 30 antenatal mothers' for the study. The tool used for the study was structured interview schedule. The data gathered were analysed by using descriptive statistics. Findings shows that among 30 adults $0(0 \%)$ were having adequate knowledge, $3(10 \%)$ were having moderately adequate knowledge and $27(90 \%)$ were having inadequate knowledge. ${ }^{9}$

This study and as well as other studies cited shows that there is a necessity to provide information for those specific at risk population. Nurses have more responsibility 
on creating knowledge among antenatal mothers by facilitating distribution of booklets, hand-outs, charts, regularly to all out patient department of hospitals health clinics in rural and urban and they can conduct workshops and camps regarding pregnancy induced hypertension in hospital setup in order to create awareness.

\section{Conclusion:}

Most of the complications, related to pregnancy induced

\section{References:}

1. Singh M. The Art and Science of Baby and Child Care. $1^{\text {st }}$ ed. New Delhi: Sagar printers and publishers; 2001.

2. Sonia HD, Sengwee T, Sven C. Risk of pre-eclampsia in first and subsequent pregnancies: prospective cohort study. BMJ 2009;338: b2255 doi:10.1136/bmj.b2255

3. Kuklina EV, Kuklina, Elena V.; M eikle, Susan F.; Jamieson, Denise J.; Whiteman, Maura K.; Barfield, Wanda D.; Hillis, Susan D.; Posner, Samuel F Hypertensive Disorders and Severe Obstetric Morbidity in the United States. Obstet Gynecol 2009; 113: 299-306.

4. Maternal mortality in 2005: estimates developed by WHO, UNICEF, UNIFPA and the World Bank, Geneva, World Health Organization, 2007.

5. Maternal HH. www.ceeindia.org/mdgs/goal2005-5hmt-18k.

6. World Health Organization Fact Sheet, M ay 2012.

7. Cousens S, Blencowe H, Stanton C, Chou D, Ahmed S, Steinhardt L, Creanga AA, Tunçalp O, Balsara ZP, Gupta S, Say L, Lawn JE. National, regional, and worldwide estimates of stillbirth rates in 2009 with trends since 1995: a systematic analysis. Lancet, 2011, Apr 16;377(9774):1319-30.

8. Soya, K, Kumari, V P Geetha, Mumthas, Kadeeja. Self-care activities of pregnancy induced hypertension and maternal outcome. Nursing Journal of India, Mar 2003.

9. Kavitha.P, Prasath AP, Krishnaraj, P. A study to assess the knowledge of antenatal mothers regarding pregnancy induced hypertension. International Journal of pharmacy practice and drug research.2012; 2(1): 1-2. hypertension are occurring due to maternal negligence or unawareness on the disease and its management. Self-care offers a real potential for improving their health status, and thus to prevent the severe form of PIH at a deteriorating health cost. Self-care would be the most effective and appropriate approach to enhance both maternal and foetal wellbeing, as well as the successful outcome of pregnancy. 